\title{
Design of Experiments of hidden resources in the tailing pond - a case study for thermal power plant in Slovakia
}

\author{
Martin Bosák* ${ }^{*}$ Petra Szaryszová, Lenka Štofová, and Jaroslav Dugas \\ University of Economics in Bratislava, Košice, Slovak Republic
}

\begin{abstract}
Thermal energy is the second most important source in Slovakia after electricity, which represents almost $13.6 \%$ of total energy production. In one of the Slovak thermal power plant Vojany (EVO) occurs by coal combustion as an undesirable slag ash mixture deposited on the tailing pond. By using environmentally sound technologies it is necessary to ensure adequate management of this waste, security and longterm stability of tailing pond. The aim of the paper is to formulate conclusions from the composition structure of EVO tailing pond and then its use. Authors realized as the main method the Design of Experiments, where the research was to investigate boreholes based on diagonal and cross-section. From the results obtained there was found that volume of tailing pond is $5,164,800 \mathrm{~m} 3$. In this volume there is $1,045,319 \mathrm{~m} 3$ of a low ash, which represents cca $20 \%$, which can be repeatedly reused in coincineration with black coal. The development of combustion technology suggests that in the near future it will be possible to use the whole volume of the examined tailing pond for co-incineration, thus reclaiming of the tailing pond basin in an environmental manner.
\end{abstract}

\section{Introduction}

Although alternative energy sources have come to the fore in the last four decades, the use of coal as a major energy source cannot be ruled out. The disposal of high amounts of fly ash from thermal power plants absorbs huge amounts of water, energy and soil. In order to meet the growing demand for energy, various environmental, economic and social problems related to the disposal of fly ash would continue to increase. [1]

The use of coal containing (30-50\%) bituminous or subbitus coal with high ash content in thermal power plants, in addition to several self-powered power plants, contributes to the non-discriminatory disposal of this industrial waste every year. The fly ash is the end residue from the combustion of pulverized bituminous or subbitus coal (lignite) in a thermal power plant furnace and consists of mineral coal components that are not completely burned. [2]

The resulting by-products from combustion of coal in the form of fly ash and bottom ash, as well as their mixtures with the residues from the flue gas desulfurization process,

\footnotetext{
${ }^{*}$ Corresponding author: martin.bosak@euba.sk
} 
cause significant economic and environmental problems. A relatively small percentage of the material finds application in construction as an additive to cement and other construction products in mining, machinery and agriculture, but the vast majority of the material that is produced every year is deposited in landfills $[3,4]$.

The advantages and disadvantages of the potential use of coal ash in soil improvement, construction, and ceramics are also considered by authors Yao et al. (2015). [5]

Jayanthi and Singh (2016) define these applications in industry as "sustainable materials" in stabilizing and modifying the soil. [2]

The use of ashes in areas such as new materials, waste management, metal recovery and agriculture is being analysed by the authors to explore new areas that enhance the positive reuse of ash, thereby helping to reduce the environmental and economic impacts of disposal.

The coal ash by-product has been classified as waste from the Environmental List of the Organization for Economic Cooperation and Development (OECD). It is not considered to be waste under the Basel Convention. However, in many countries this industrial byproduct has not been used correctly, but rather has been neglected as a waste. In China, approximately 100 million tonnes of coal-fired products are produced each year. [6]

Takhelmayum et al. (2013) realized a study in a developing country India. As a result of industrial development, there is an increase in energy demand, resulting in the construction of several coal-fired power plants. This development has raised the issue of safe disposal or beneficial use of a large number of by-products such as fly ash, which is mainly used in construction industry. However, the production rate is higher than consumption. Unused fly ash is placed eg. to retaining ponds, lagoons, landfills and accumulating debris of ash. [7]

According to a report of association by American Coal Ash, agriculture uses reclamation and construction engineering $32 \%$ of fly ash, $30 \%$ of bottom ash, $94 \%$ of boiler slag and $9 \%$ flue gas desulphurization sludge. At present, the production of fly ash in India is around 112 tons and is likely to exceed 170 MT by the end of the year. In 2015, the use of fly ash was $100 \%$ in Italy, Denmark and the Netherlands with an annual production of 2 MT, $50-85 \%$ in the USA and Germany and $45 \%$ in China (Table 1). In India, the use of fly ash has increased from $3 \%$ in the 1990 s to $38 \%$ in 2005 . The reason for the low use of fly ash in India is the unavailability of appropriate cost-effective technologies. $[6,8]$

Table 1. Creation and using of fly ash in different countries.

\begin{tabular}{|c|c|c|}
\hline Country & Production of fly ash (in million ton/year) & Use of fly ash (\%) \\
\hline India & 112 & 38 \\
\hline China & 100 & 45 \\
\hline USA & 75 & 65 \\
\hline Germany & 40 & 85 \\
\hline United Kingdom & 15 & 50 \\
\hline Australia & 10 & 85 \\
\hline Canada & 6 & 75 \\
\hline France & 3 & 85 \\
\hline Denmark & 2 & 100 \\
\hline Italy & 2 & 100 \\
\hline Netherlands & 2 & 100 \\
\hline
\end{tabular}

Disposal of fly ash from power plants causes significant economic and environmental problems. A relatively small percentage of the material finds application as an additive in cement and other construction products, but the vast majority of material produced annually consists of ash dams or similar landfills. This unproductive land use and related long-term financial burden due to maintenance has led to the realization that alternatives to using fly 
ash as a value-added product that are not included in building materials are needed. The use of ashes in areas such as new materials, waste management, metal recovery and agriculture is analyzed by the authors to explore new areas that will enhance the positive reuse of fly ash, helping to reduce the environmental and economic impacts of disposal. Fly ash mixture is the subject of research studies in many countries of the world [9-14], in Asia, China [5, 8], India [6] and also in Europe, in Poland [15], Italy [16] and in Slovakia [17].

\section{Materials and Methods}

This chapter presents development of original remediation technologies for unconventional tailing pond dross ashes mixture disposal. This technology uses structured layers of land, soil and stabilization material. The reason is to replace previous legislative solution by the overlapping of hydrofilm material and drainage system.

\subsection{Characteristics and purpose of the tailing pond}

The biggest fossil fuel plant in Slovakia is EVO, where mainly semi-anthracite coal from Ukraine and Russia is used as fuel. Currently, for disposal of waste products from coal combustion the plant operates two facilities:

1. Tailing ponds with dross ashes mixture,

2. Dump with stabilization material tailing.

The two-deck tailing pond of sludge-ash mixture (Cassette No. 1 is already closed) is located near the plant, from which it is separated by a state road leading to the villages of Ižkovce and Beša. It serves as a repository for the slag-ash mixture, which is conveyed from the power plant boilers through the pipeline. This substance is produced by the combustion of coal. The crushed slag is conveyed through the navigating channels from the individual blocks to the dredging station. The mixture of water, slag and fly ash is conveyed further by dredging pumps through $300 \mathrm{~mm}$ diameter pipelines to the tailing pond.

Stabilization material is a by-product of the desulfurization of power plant technology, combustion processes and is deposited on a separate stabilizer landfill. [2]

\subsection{Technical data of tailing pond}

Safety and operation oversight within the relevant legislation of tailing pond of EVO plant Vojany is needed because it is water work. On the verge of PLA Latorica, on the left bank of the river Laborec it was built in 1965 to store dross ash mixture and located in the administrative area of village Drahňov and Vojany. It is bounded on all sides by raising grass covered embankments. Two separate approximately the same cassettes create the tailing pond:

1. Cassette No. 1 - 29 ha (with dam 47.2 ha), (Fig. 1)

2. Cassette No. 2 - 27 ha. (with dam 48.12 ha).

Technical data of the tailing pond are given in Table 2. The original dams of the tailing ponds were built up to the height of $104.5 \mathrm{~m}$ a. s. 1. and their total increase to dimension $116 \mathrm{~m}$ a. s. 1. it was built by four increases of dikes.

Table 2. Base parameters of tailing pond.

\begin{tabular}{|c|c|c|}
\hline Parameter & Cassette No. 1 & Cassette No. 2 \\
\hline Base Area & $52.8 \mathrm{ha}$ & 47.1 ha \\
\hline Surface area with dam & $47.2 \mathrm{ha}$ & $43.1 \mathrm{ha}$ \\
\hline Cassette surface area & $29 \mathrm{ha}$ & 27 ha \\
\hline Maximum Drift Dimension & $115.00 \mathrm{~m}$ a. s. 1. & $115.00 \mathrm{~m}$ a. s. 1.
\end{tabular}


Table 2. Continued.

\begin{tabular}{|c|c|c|}
\hline The dimension of simultaneously stored material & $113.50 \mathrm{~m}$ a. s. 1. & $112.00 \mathrm{~m} \mathrm{a}$. s. 1. \\
\hline Total volume of ash stored & $7580000 \mathrm{~m}^{3}$ & $5760000 \mathrm{~m}^{3}$ \\
\hline Dispositional volume & filled & $850.000 \mathrm{~m}^{3}(30.06 .2015)$ \\
\hline Total basin area of tailing pond & \multicolumn{2}{|c|}{$300 \mathrm{ha}$} \\
\hline Length of perimeter dams & \multicolumn{2}{|c|}{$98.00-100.00 \mathrm{~m}$ a. s. 1.} \\
\hline Height above sea level of tailing pond & \multicolumn{2}{|c}{}
\end{tabular}

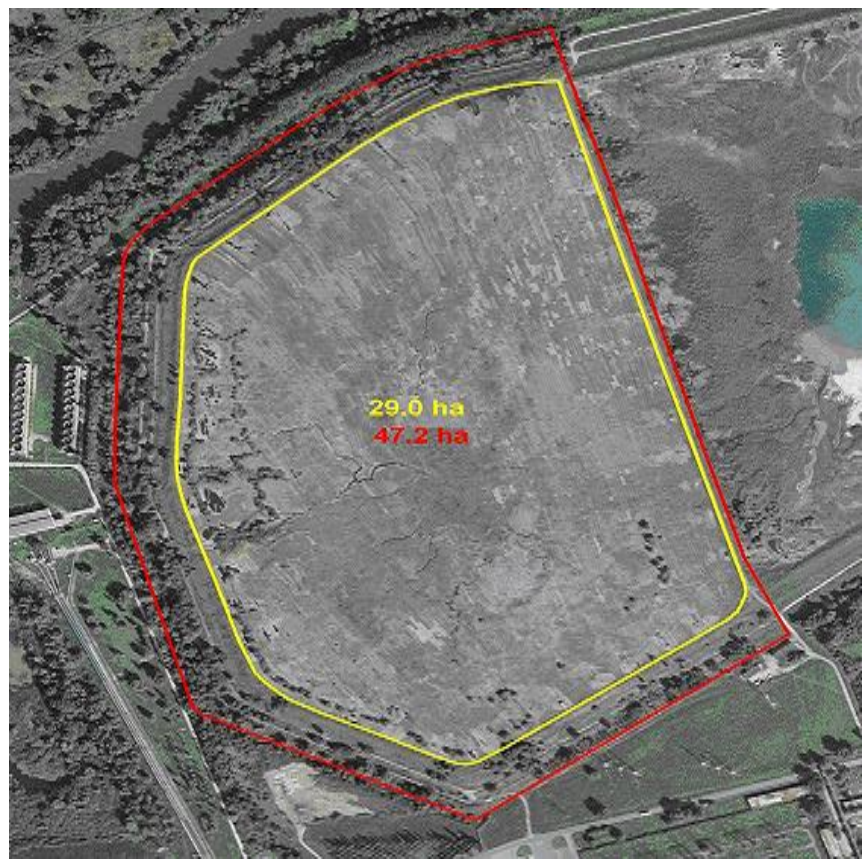

Fig. 1. Cassette No. 1 at tailing pond.

Hydraulic transport of coal combustion products and the self-imposed dump with stabilization material is stored on the tailing pond with two cassettes of dross ash mixtures. The cassettes are separated from each other by a dividing dam, which originally had the function of a perimeter dam of the Cassette No. 1.

Perimeter dams were built by gradual increase in the years $1970-1980$. The tailing pond is created by dams around the perimeter. Currently the entire slope of the tailing pond - Cassette No. 1 shows no deformation or instability. No other materials were stored in this space.

\subsection{Method Design of Experiments}

The Design of Experiments (DOE) method is a method of planned experiments. This is an analytical technique that aim is to obtain relevant results by testing multiple values. It is a method in which empirical data are processed to predict possible states. There are several variations of this method.

The DOE method is used to test complex tasks where the end result is a combination of many factors. Thus, the DOE method is based on testing combinations of different values of factors that affect the outcome and thereby narrowing the number of combinations tested 
to those essential in terms of overall outcome. Thus, the DOE method significantly reduces the number of tests required and is the most used in research and development.

We call the experiment a systematic procedure performed under controlled conditions in order to detect an unknown effect, test or hypothesis. In process analysis, attempts are often made to assess which process inputs have a significant impact on the output of processes and what the target level of these inputs should be to achieve the desired result. Experiments can be designed in many different ways to collect this information.

Designing experiments is a discipline of mathematical statistics that deals with data collection in a situation where the information is loaded with randomness. For example, a three-level experiment, where we observe the impact of three factors on approach response, where we combine all possible levels of factors (the so-called full three-factor experiment), assumes that a linear model will be used and that it well describes the input/output relationship. There is no possibility to verify whether a linear model is suitable or not, so one or more so-called central points (CP) are added to the two-level plan. When analysing the experiment, we examine, using $\mathrm{CP}$, whether a linear model is sufficient for dependency estimation, or a non-linear response model is to be considered.

\section{Results}

The position of the individual wells on the tailing pond was marked by the method of planned experiments DOE. The boreholes themselves were deployed on a two-dimensional surface, the third dimension, i.e. the depth was done for all available drilling values up to the cassette subsoil (16m). Samples were taken from each meter of the well. Since the CP can be understood as the arithmetic mean of the distance of the two opposing vertices of the quadrilateral (points $1,2,3,8$ ), the next measurement was made at the point corresponding to the "golden section", at both diagonals of the basic quadrilateral (CP 4 and 5).

The last two boreholes (CP 6 and 7) were placed in such a way that with the three outer points of the said quadrilateral they form a boundary pentagon whose peaks lie at the boundary of possible drilling, i.e. the distance from the individual dykes was determined in such a way that to avoid damaging the dam in the case of a technically constructed borehole.

Table 3 shows the coordinates of the individual points, their altitude and their distance from the CP.

The measured experimental results were recorded and the mean values along with minimum and maximum of data for individual meter layers of the longitudinal section of the tailing pond A-A and its cross section B-B. (Table 4)

Both of the sections A-A and B-B go through the central point and give a visual impression of the percentage of undershot of the slug ash mixture on the EVO Cassette No. 1.

Table 3. Base parameters of tailing pond.

\begin{tabular}{|c|c|c|c|c|}
\hline Point & Y & X & m a. s. I. & Distance from CP [m] \\
\hline CP & 210931.10 & 1259442.29 & 114.25 & - \\
\hline 1 & 211108.31 & 1259495.46 & 115.05 & 185.01 \\
\hline 2 & 210983.86 & 1259258.75 & 115.02 & 190.97 \\
\hline 3 & 210750.54 & 1259392.76 & 114.93 & 187.23 \\
\hline 4 & 210971.26 & 1259456.33 & 114.33 & 42.54 \\
\hline 5 & 210914.99 & 1259502.11 & 112.45 & 61.95 \\
\hline 6 & 211004.85 & 1259809.69 & 114.92 & 374.73 \\
\hline 7 & 210752.29 & 1259795.06 & 115.07 & 395.50 \\
\hline 8 & 210875.21 & 1259649.50 & 112.05 & 214.62 \\
\hline
\end{tabular}


The following Fig. 2 shows 9 points of sampling points on the tailing pond - Cassette No. 1.

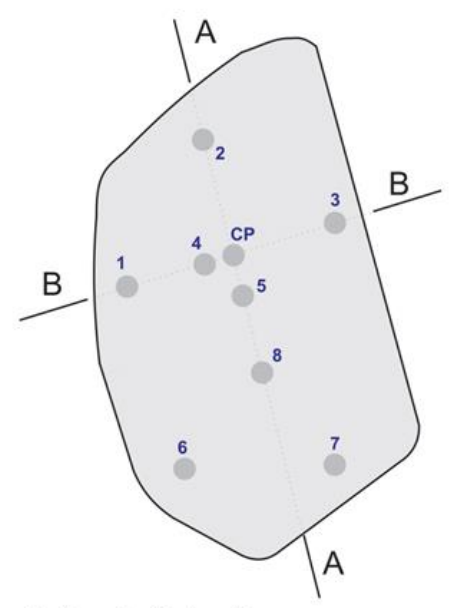

A - Longitudinal section
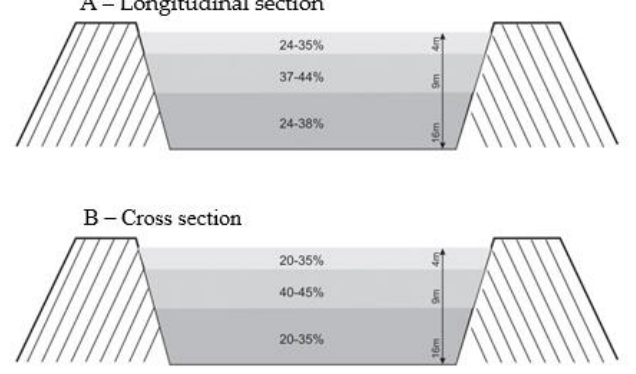

Fig. 2. Points of the depth boreholes at the bottom of the tailing pond.

Table 4. Base parameters of tailing pond.

\begin{tabular}{|c|c|c|c|c|c|c|}
\hline & \multicolumn{3}{|c|}{ Longitudinal section A-A } & \multicolumn{3}{c|}{ Cross section B-B } \\
\hline Depth & Average & Min. & Max. & Average & Min. & Max. \\
\hline $1 . \mathrm{m}$ & 29.99 & 27.45 & 32.54 & 20.91 & 17.62 & 24.20 \\
\hline $2 . \mathrm{m}$ & 32.71 & 26.47 & 41.03 & 28.08 & 20.78 & 39.41 \\
\hline $3 . \mathrm{m}$ & 24.07 & 21.14 & 30.27 & 23.53 & 18.86 & 30.80 \\
\hline $4 . \mathrm{m}$ & 30.95 & 24.87 & 35.20 & 34.17 & 28.58 & 39.05 \\
\hline $5 . \mathrm{m}$ & $\mathbf{4 0 . 3 5}$ & 33.18 & 47.17 & $\mathbf{4 1 . 6 3}$ & 39.90 & 43.16 \\
\hline $6 . \mathrm{m}$ & $\mathbf{3 7 . 3 0}$ & 34.78 & 40.89 & $\mathbf{4 0 . 1 9}$ & 35.73 & 42.58 \\
\hline $7 . \mathrm{m}$ & $\mathbf{4 3 . 2 7}$ & 40.10 & 51.06 & $\mathbf{4 3 . 4 5}$ & 38.38 & 51.06 \\
\hline $8 . \mathrm{m}$ & $\mathbf{3 8 . 7 1}$ & 24.37 & 46.87 & $\mathbf{4 1 . 0 6}$ & 36.25 & 45.13 \\
\hline $9 . \mathrm{m}$ & $\mathbf{3 9 . 0 5}$ & 30.60 & 49.54 & $\mathbf{4 0 . 1 3}$ & 37.32 & 44.78 \\
\hline $10 . \mathrm{m}$ & 37.87 & 26.35 & 45.26 & 33.65 & 23.53 & 45.26 \\
\hline $11 . \mathrm{m}$ & 32.80 & 29.96 & 34.67 & 32.45 & 27.53 & 37.36 \\
\hline $12 . \mathrm{m}$ & 24.06 & 13.00 & 33.55 & 28.12 & 27.98 & 28.23 \\
\hline $13 . \mathrm{m}$ & 24.21 & 17.34 & 27.93 & 20.65 & 20.65 & 20.65 \\
\hline $14 . \mathrm{m}$ & 26.83 & 23.51 & 29.48 & 29.17 & 20.02 & 38.32 \\
\hline $15 . \mathrm{m}$ & 26.06 & 14.66 & 35.85 & 32.92 & 24.01 & 41.83 \\
\hline $16 . \mathrm{m}$ & 31.92 & 26.10 & 43.48 & 25.31 & 19.90 & 30.72 \\
\hline
\end{tabular}

The measured and calculated results divide the depth of the tailing pond basin into 3 layers, while in the middle layer is located slug ash mixture with a low ash of over 40$50 \%$. 
If we consider the geodetic survey of the cassette from $1 \mathrm{~m}$ (115 $\mathrm{m}$ above sea level) to a depth of $18-20 \mathrm{~m}$ from the surface (up to $95 \mathrm{~m}$ above sea level), we get a volume of $5,164,800 \mathrm{~m}^{3}$ and in this volume there is $\min .25-30 \%$ low ash.

\section{Conclusion}

The results show that the among of slug ash content in the tailing pond mixture with a under-firing in the range of $15-50 \%$, with a mean depth of $20-35 \%$ at a depth of 1-5 meters, a depth of 5-9 meters in the range of 39-44\% and at a depth of 9-16 meters in the range of $25-38 \%$.

Due to the total area of the tailing pond, there is a large amount of slag ash mixture, which can be repeatedly reused in coincineration with black coal. The development of combustion technology suggests that in the near future it will be possible to use the whole volume of the examined tailing pond for co-incineration, thus reclaiming of the tailing pond basin in an environmental manner. In order to clarify the values of the under firing of the slug ash mixture, it is necessary to continue the experiment and carry out further boreholes in the tailing pond to clarify the results obtained, which will follow in the next stage of the project.

\section{References}

1. K. M. Nilesh, D. P. Sachin, B. S. Dhananjay, B. A. Sanjay, Pol. J. Environ. Stud., 21 (2012)

2. P. N. Jayanthi, D. N. Singh, Advances in Civil Engineering Materials, 5 (2016)

3. M. Ahmaruzzaman, Prog. Energ. Combust., 36 (2010)

4. M. Basu, M. Pande, P. B. S. Bhadoria, S. C. Mahapatra, Progress in Natural Science, 19 (2009)

5. Z. T. Yao, X. S. Ji, P. K. Sarker, J. H. Tang, L. Q. Ge, M. S. Xia, Y. Q. Xi, EarthScience Reviews, 141 (2015)

6. ACAA (2021) https://www.acaa-usa.org

7. G. Takhelmayum, A. L. Savitha, G. Krishna, International Journal of Engineering Science and Innovative Technology - IJESIT, 2 (2013)

8. R. Xu, F. Li, Environmental Science and Information Application Technology, 1 (2009)

9. I. Jiménez, G. Pérez, A. Guerrero, B. Ruiz, Int. J. Miner. Proc., 8 (2017)

10. J. Kalembkiewicz, U. Chmielarz, Pol. J. Environ. Stud., 22 (2013)

11. W. Kępys, Z. Piotrowski, R. Pomykała, A. Grzywa, Pol. Min. Eng. Soc., 15 (2014)

12. J. Kierczak, K. Chudy, Pol. J. Environ. Stud., 23 (2014)

13. O. Kizinievic, V. Kizinievic, Constr. Build. Mater., 127 (2016)

14. R. Rajamma, R. J. Ball, L. A. C. Tarelho, G. C. Allen, J. A. Labrincha, V. M. Ferreira, J. Hazard. Mater., 172 (2009)

15. E. Tkaczewska, R. Mróz, G. Łój, Constr. Build. Mater., 28 (2012)

16. R. S. Iyer, J. A. Scott, Resources, Conservation and Recycling, 31 (2001)

17. M. Bosák, Z. Hajduová, M. Majerník, P. Andrejovský, Pol. J. Environ. Stud., 24 (2015) 